\title{
Mutations in SURF1 are important genetic causes of Leigh syndrome in Slovak patients
}

\author{
Daniel Danis ${ }^{1}$, Katarina Brennerova ${ }^{2}$, Martina Skopkova ${ }^{1}$, Timea Kurdiova ${ }^{1}$, Jozef Ukropec ${ }^{1}$, \\ Juraj Stanik ${ }^{1,2}$, Miriam Kolnikova ${ }^{3}$, Daniela Gasperikova ${ }^{1}$ \\ ${ }^{1}$ Institute of Experimental Endocrinology, Biomedical Research Center, Slovak Academy of Sciences, Bratislava, Slovakia; \\ ${ }^{2}$ Department of Paediatrics, Medical Faculty of Comenius University and Children Faculty Hospital, Bratislava, Slovakia; \\ ${ }^{3}$ Department of Pediatric Neurology, Medical Faculty of Comenius University and Children Faculty Hospital, Bratislava, \\ Slovakia \\ E-mail: daniela.gasperikova@savba.sk
}

\begin{abstract}
Objectives. Leigh syndrome is a progressive early onset neurodegenerative disease typically presenting with psychomotor regression, signs of brainstem and/or basal ganglia disease, lactic acidosis, and characteristic magnetic resonance imaging findings. At molecular level, deficiency of respiratory complexes and/or pyruvate dehydrogenase complex is usually observed. Nuclear gene SURF1 encodes an assembly factor for cytochrome c-oxidase complex of the respiratory chain and autosomal recessive mutations in SURF1 are one of the most frequent causes of cytochrome c-oxidase-related Leigh syndrome cases. Here, we aimed to elucidate the genetic basis of Leigh syndrome in three Slovak families.

Methods and results. Three probands presenting with Leigh syndrome were selected for DNA analysis. The first proband, presenting with atypical LS onset without abnormal basal ganglia magnetic resonance imaging findings, was analyzed with whole exome sequencing. In the two remaining probands, SURF1 was screened by Sanger sequencing. Four different heterozygous mutations were identified in SURF1: c.312_321delinsAT:p.(Pro104Profs ${ }^{\star} 1$ ), c.588+1G>A, c.823_833+7del:p. (?) and c.845_846del:p.(Ser282Cysfs ${ }^{\star}$ ). . All the mutations are predicted to have a loss-of-function effect.

Conclusions. We identified disease-causing mutations in all three probands, which points to the important role of SURF1 gene in etiology of Leigh syndrome in Slovakia. Our data showed that patients with atypical Leigh syndrome phenotype without lesions in basal ganglia may benefit from the whole exome sequencing method. In the case of probands presenting the typical phenotype, Sanger sequencing of the SURF1 gene seems to be an effective method of DNA analysis.
\end{abstract}

Key words: Leigh syndrome, mitochondrial disease, SURF1, whole exome sequencing

Leigh syndrome (LS; MIM \#256000) is a genetically heterogeneous disease with presentation usually starting in infancy with subacute necrotizing encephalomyopathy (Leigh 1951). Other typical features include neurodevelopmental regression, signs and symptoms of brainstem and/or basal ganglia disease, lactic acidosis, and characteristic findings in magnetic resonance imaging (MRI). However, patients with LS may also have atypical clinical course without lactic acidosis or characteristic brain lesions (Rahman et al. 1996).

Biochemically, generalized defects of mitochondrial respiratory complexes I (NADH dehydrogenase), II (succinate dehydrogenase), IV (cytochrome $c$ oxidase)

Corresponding author: Daniela Gasperikova, RNDr, D.Sc., Laboratory of Diabetes and Metabolic Disorders, Institute of Experimental Endocrinology, Biomedical Research Center, Slovak Academy of Sciences, Dubravska cesta 9, 84505 Bratislava, Slovakia; phone: +421 905681 978; e-mail: daniela.gasperikova@savba.sk. 
or the pyruvate dehydrogenase complex (PDHc) have been discovered in people with LS. Until recently, identification of the underlying genetic cause has been challenging due to the large number of genes encoding subparts of respiratory complexes and the PDHc. In total, more than 75 genes have been identified as monogenic cause of LS so far (Lake et al. 2016).

Moreover, mutations in genes leading to LS are inherited in one of several patterns, depending on the gene involved. Mutations in genes encoded by mitochondrial DNA, for example MT-ND3 (MIM *516002, NADH dehydrogenase subunit 3), are inherited maternally. Mendelian forms of LS include $\mathrm{X}$-linked recessive inheritance due to mutations in the PDHA1 (MIM *300502, PDHc E1-alpha subunit) or autosomal recessive inheritance due to mutations in nuclear genes encoding subunits of respiratory complexes or in their assembly factors, for instance SURF1 (MIM *185620, surfeit 1).

Due to this remarkable genetic heterogeneity, the conventional single gene Sanger sequencing is not effective. However, the next generation sequencing methods allow to simultaneously screen large panels of genes involved in LS, all exons from all known genes (whole exome sequencing, WES), or even the whole genome of the individual. The intent of the present study was to identify the genetic cause of three Slovak patients with LS syndrome.

\section{Methods}

Whole exome sequencing. Peripheral blood samples were collected from probands and their parents and genomic DNA was isolated using standard procedures. DNA was randomly fragmented by Covaris into lengths between 200 and $400 \mathrm{bp}$. AdA adapters were ligated to the 5' and 3' ends. Fragments were then amplified by PCR and subsequently subjected to hybridization with exon capture kit probes (BGI 59M Human Exome kit). The captured fragments were purified by Dynabeads ${ }^{\mathrm{Tm}} \mathrm{M}-280$ Beads and further amplified using PCR. The PCR product was then circularized and digested with Ecop15I endonuclease. After second round of purification on beads, the AdB adapters were ligated to both ends of the purified fragments. Finally, the fragments were circularized and used as a library for sequencing on Complete Genomics Black Bird platform (BGI, Shenzen, China).

Sequencing data were processed by BGI's standard bioinformatics pipeline which encompassed base calling, alignment of generated reads to the GRCh37 reference genome without the unplaced or alternate loci and variant calling. Aligned reads and called variants were obtained in standard bioinformatics formats and subjected to following in-house pipeline.

Variants were decomposed and normalized using $v t$ (Tan et al. 2015) and the Variant effect predictor (McLaren et al. 2016) was used to annotate the variants with respect to their potential effects on genes and transcripts. Additional annotations such as minor allele frequencies (MAF) were extracted from databases dbSNP, 1000 Genomes, Exome Sequencing Project (ESP) and Exome Aggregation Consortium (ExAC). In-silico scores from multiple prediction algorithms (CADD, PolyPhen, SIFT) were collected using Gemini framework (Paila et al. 2013).

Then, variants were filtered to remove variants with MAF $\geq 0.01$ (dbSNP, 1000 Genomes, ESP or ExAC) or variants lying outside of regions of 1595 genes annotated with Gene Ontology Term mitochondrion GO:0005739 (obtained from the BioMart web portal grch37.ensembl.org/biomart/martview/, accessed on April 2017).

Sanger sequencing was performed in order to confirm the presence of candidate variants in the genome of all participating family members. Primers for amplification of all 9 exons of $S U R F 1$ with polymerase chain reaction were designed using Primer BLAST software (NM_003172.3 used as reference, primer sequences available on request). Unincorporated primers and nucleotides were removed from PCR products using Exo I and FastAP ${ }^{\mathrm{TM}}$ enzymes. Sequencing reactions of purified PCR products were carried out using BigDye Terminator v3.1 chemistry and separated on ABI 3500 genetic analyzer (Applied Biosystems, Foster City, USA) according to manufacturer's instructions. The sequencing data was analyzed using SeqScape software.

Mitochondrial OXPHOS activities. Activities of complexes II and IV of mitochondrial respiratory chain were measured in patient 1 as described elsewhere (Skopkova et al. 2017). Activities of complexes I, II, III, I-III, II-III, and IV were measured in skeletal muscle tissue of patient 2 (Mitolab, Prague, Czech Republic).

Biochemical analyses. All metabolic and biochemical parameters were measured in the serum, cerebrospinal fluid, and urine in central laboratory of the Children Faculty Hospital in Bratislava by standardized methods.

Ethics. Parents of the probands provided written informed consent for this study, which was approved by the Ethics committees of the Children Faculty Hospital in Bratislava, Slovakia and adhered to the tenets, outlined in the Declaration of Helsinki. All patients involved were Slovaks and of Caucasian origin. 
Figure 1. Pedigrees of the analyzed families. Squares represent males, circles represent females, gray symbol is for affected individuals, open for unaffected persons. The proband is indicated by the arrow. Symbols below each individual represent presence/absence of the mutations. Legend: M1: c.845_846del, M2: c.823_833+7del, M3: c.312_321delinsAT, M4: c. $588+1 \mathrm{G}>\mathrm{A}, \mathrm{N}$ : wild type, SB: stillbirth.

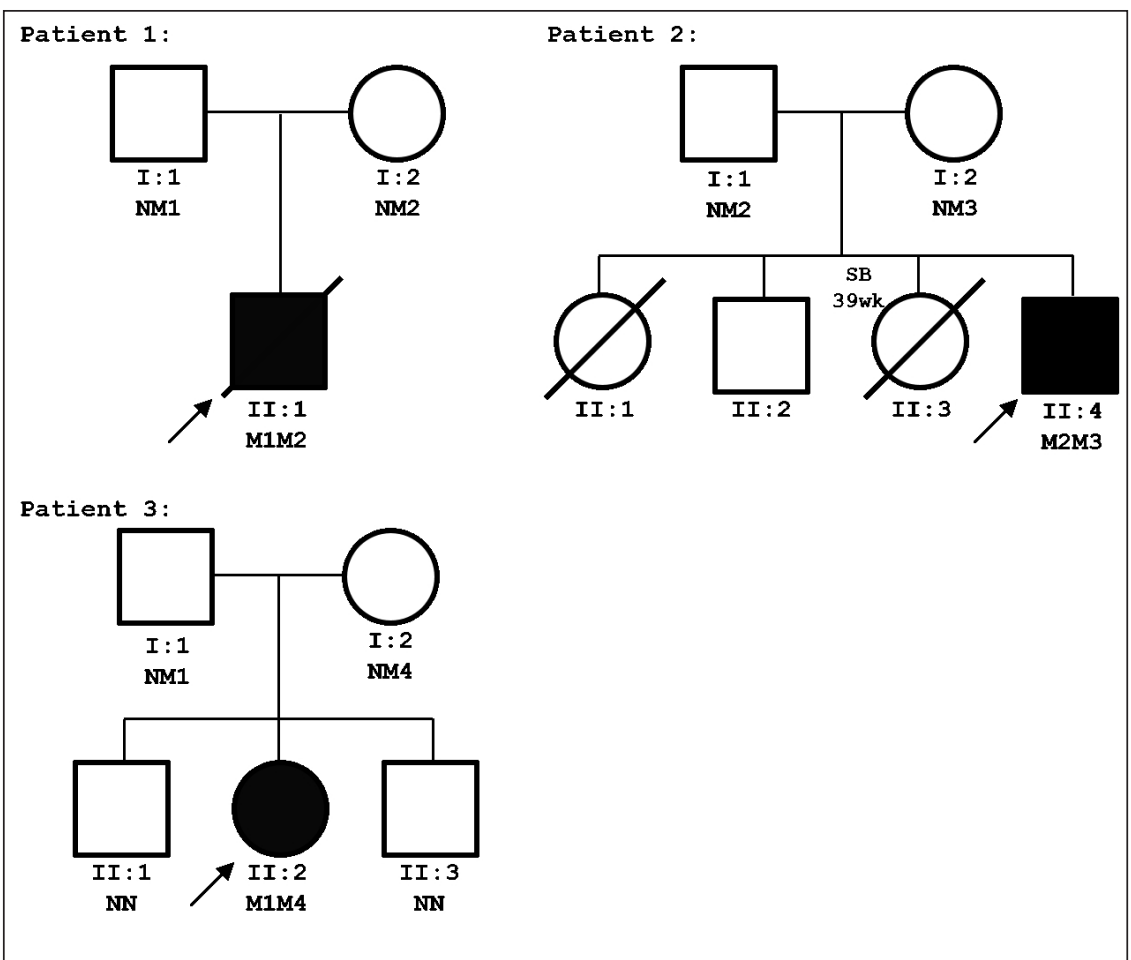

\section{Case reports}

Patient 1, male, was the $1^{\text {st }}$ child of non-consanguineous parents with no metabolic disease reported in their family history (Figure 1). He was born at term with normal postnatal development until the age of 6 months when he was diagnosed with failure to thrive, hypotonia, and psychomotor regression. Metabolic work-up revealed increased serum lactate $(9.19 \mathrm{mmol} / \mathrm{l}$, normal range: $0.7-2.10 \mathrm{mmol} / \mathrm{l})$, increased cerebrospinal fluid (CSF) lactate $(10.49 \mathrm{mmol} / \mathrm{l}$, normal range: $1.20-$ $2.10 \mathrm{mmol} / \mathrm{l})$ and decreased CSF glucose $(3.2 \mathrm{mmol} / \mathrm{l}$, normal range: $4.2-6.1 \mathrm{mmol} / \mathrm{l})$. Urine organic acid profiling discovered moderately increased excretion of the metabolites of Krebs cycle and respiratory chain (citrate $1014.9 \mu \mathrm{mol} / \mathrm{mmol}$, aconitate $124.0 \mu \mathrm{mol} / \mathrm{mmol}$, $\alpha$-ketoglutarate $1682.5 \mu \mathrm{mol} / \mathrm{mmol}$, succinate $705.5 \mu \mathrm{mol} / \mathrm{mmol}$,fumarate $17.6 \mu \mathrm{mol} / \mathrm{mmol}$, malate $14.1 \mu \mathrm{mol} / \mathrm{mmol}$, values as ratios to creatinine). Cerebral MRI showed areas of high signal in T2-weighted images predominantly in supra and infratentorial white matter on both sides, with acute manifestations without any lesions in the basal ganglia (Figure 2A,B,C). Clinical and laboratory findings in our patient were pointing to a mitochondrial disorder. However, treatment with a ketogenic diet (with aim to decrease high levels of serum and CSF lactate), oral thiamine $(100 \mathrm{mg} / \mathrm{d})$, riboflavin $(50 \mathrm{mg} / \mathrm{d}), \mathrm{L}$-carnitine $(250 \mathrm{mg} / \mathrm{d})$, coenzyme Q10 $(30 \mathrm{mg} / \mathrm{d})$, vitamin C $(25 \mathrm{mg} / \mathrm{d})$ and sodium bicarbonate $4.2 \%$ supplementation was not able to prevent gradual worsening of patient's condition. At the age of 11 months, the child progressed in hypotonia, hypotrophy, and sleepiness. Increased serum lactate $(5.21 \mathrm{mmol} / \mathrm{l}$, normal $0.7-2.10 \mathrm{mmol} / \mathrm{l}$ ) was observed. Decreased activities of complexes II and IV of mitochondrial respiratory chain were observed in muscle tissue. MRI revealed progression of changes in T2-weighted images displaying acute large areas of bilateral pathologic high signal of periventricular to central white matter supra and infratentorially as well as demyelination of brainstem, midbrain, and the basal ganglia (Figure 2D,E,F). Despite the treatment, progressive deterioration lead to patient's death at the age of 1 year.

Patient 2, male, was the $4^{\text {th }}$ child of non-consanguineous parents with no metabolic disease reported in the family (Figure 1). The eldest sister presented with hypotrophy, strabismus, postural instability after a fever episode at 10 months of age and died in 7 years after a febrile illness accompanied by respiratory distress. The elder brother is in good health; the elder sister was stillborn after uneventful pregnancy. The proband has been followed since his birth due to 

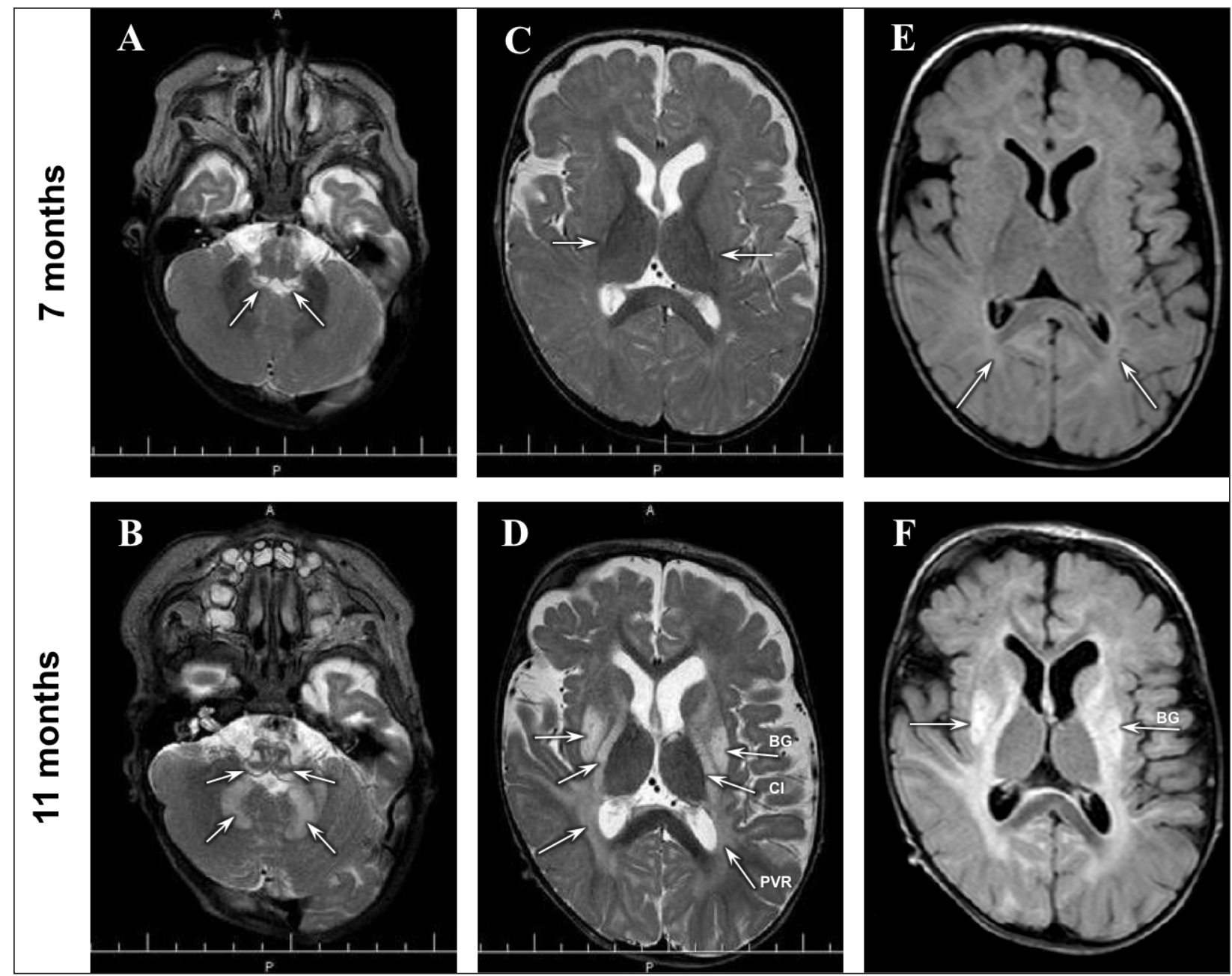

Figure 2. MRI of the patient 1 at the age of 7 months, and 11 months. A) T2W, 7 months bilateral hyperintense lesions in dorsal pons region (arrows); B) T2W, 11 months, bilateral hyperintense lesions in pons and ncl. dentatus (arrows), visible progression; C) T2W, 7 months, changes of white matter signal in regions of crus posterius capsulae internae; D) T2W, 11 months, symmetrical signal changes of white matter in periventricular regions (PVR), capsulae internae (CI) and basal ganglia (BG); E) FLAIR, 7 months, mild signal changes of white matter in periventricular occipital regions (arrows), no lesions in basal ganglia; F) FLAIR, 11 months, symmetrical hyperintense lesions of white matter in occipital and temporal regions, including basal ganglia (BG).

severe perinatal asphyxia (Apgar score 1/4/6), with mild developmental delay followed by hypotonic syndrome, convergent strabismus and horizontal nystagmus. At 4 years of age, he was examined due to growth delay and hypertrichosis. Cerebral MRI showed postischemic lesions in thalamus, cerebellum, and brainstem. At 6 years, psychomotoric regression accompanied by nystagmus, ataxia, ptosis, polyneuropathy, speech deterioration, elevated serum lactate levels (1.41-2.77 mmol/l, normal range: $0.7-2.10 \mathrm{mmol} / \mathrm{l}$ ) and elevated CSF lactate $(3.37 \mathrm{mmol} / 1$, normal range: $1.20-2.10 \mathrm{mmol} / \mathrm{l}$ ) were observed. New MRI examination showed T2-weighted hyperintense signal of white matter in cerebellar hemisphere, brainstem, and periaqueductal grey matter. These MRI findings corresponded to LS. Activities of complexes I-IV and PDHc were measured in muscle tissue and significant decrease in activities of complexes I, I-III and IV was observed (Mitolab, Prague). Currently, the $2^{\text {nd }}$ proband is 16 years old and suffers from spastic quadriparesis, oculomotor disorder, cerebellar syndrome, muscle weakness (no progression during the last 4 years), supraventricular tachycardia, and symptomatic epileptic seizures. He is also dependent on the wheelchair and nocturnal ventilatory support.

Patient 3, female, is the $2^{\text {nd }}$ child of non-consanguineous parents with no metabolic disorder present in family history, both her elder and younger siblings 
are healthy (Figure 1). She was born at term after an uneventful pregnancy. During the first year of life, failure to thrive and psychomotoric development delay was observed. At 18 months, she presented hypotonia, macrocephaly, and hypotrophy. Metabolic investigation revealed elevated serum lactate (fasting $2.87 \mathrm{mmol} / \mathrm{l}$, postprandial $2.52 \mathrm{mmol} / \mathrm{l}$, normal range: $0.7-2.10 \mathrm{mmol} / \mathrm{l})$, elevated CSF lactate $(4.00$ $\mathrm{mmol} / \mathrm{l}$, normal range: $1.2-2.10 \mathrm{mmol} / \mathrm{l}$ ) and elevated CSF $3-\mathrm{OH}$ butyrate $(3.493 \mathrm{mmol} / \mathrm{l}$, normal range: 0.03-0.30 mmol/l). MRI showed T2-weighted symmetric hyperintense signal changes of basal ganglia, midbrain, brainstem, and periaqueductal region. The patient 3 is currently 2.5 years old and she is treated with a thiamin supplementation $(150 \mathrm{mg} / \mathrm{d})$, riboflavin $(50 \mathrm{mg} / \mathrm{d})$ coenzyme Q10 $(60 \mathrm{mg} / \mathrm{d})$, vitamin C $(100 \mathrm{mg} / \mathrm{d})$ and Shohl's alkaline solution for acidosis correction. Her current clinical state is significantly impaired, presenting with generalized muscle weakness, severe hypotrophy, breathing and swallowing difficulties, macrocephaly, facial dysmorphism, hypertrichosis, and developmental stagnation.

\section{Results}

The DNA of Patient 1 was analyzed using whole exome sequencing. Sequencing generated $\sim 518$ millions of uniquely mapped reads with mapping quality $\geq 30$, covering $93.45 \%$ of target regions at least $20 \times$. The overall mean sequencing depth was $162.22 \times$. In total, 106384 variants were called, transition vs. transversion ratio and heterozygous vs. non-reference homozygous genotypes ratio were within the recommended boundaries for WES data (Guo et al. 2013; Wang et al. 2015); 4664 variants were novel and 98070 variants were present in 1000 Genomes or dbSNP databases with minor allele frequency (MAF) more than 0.01 .

In total, 226 rare $(\mathrm{MAF}<0.01)$ or novel variants were localized in the mitochondrion-related genes. Two heterozygous deletions c.845_846del:p.(S282Cfs ${ }^{\star}$ ) and c.823_833+7del:p.(?) were identified in SURF1 (Figure 2). Sanger sequencing of all 9 exons and up to $100 \mathrm{bp}$ of neighboring intronic sequences of SURF1 was performed in the patient 2 and patient 3. Mutations c.823_833+7del:p.(?) and c.312_321delinsAT:p. (Pro104Profs ${ }^{\star} 1$ ) were discovered in heterozygous state in patient 2 (Figure 2). The DNA of patient 3 harbored mutations c.845_846del:p.(Ser282Cysfs $\left.{ }^{\star} 9\right)$ and c. $588+1 \mathrm{G}>\mathrm{A}:$ p.(?), both of them in heterozygous state (Figure 2). Compound heterozygous genotype of all three patients was validated by Sanger sequencing of the parental DNA. Summary of identified mutations and their impact on protein function is presented in Table 1. Positions of the mutations relative to the SURF1 gene are depicted in Figure 3.

\section{Discussion}

In the presented cases, we have identified four different mutations in the SURF1 gene (Table 1) in three unrelated Slovak patients with clinically diagnosed Leigh syndrome. Phenotypes of the patients are summarized in Table 2.

SURF1 is a nuclear gene which consists of nine exons spread over approximately $4.7 \mathrm{~kb}$ in locus 9q34.2. Human SURF1 cDNA is $\sim 1 \mathrm{~kb}$ long and encodes a 300 amino acid protein product. The protein contains two predicted transmembrane domains and acts as an important factor in cytochrome coxidase (COX) assembly and maintenance. COX is the last

Table 1

Summary of identified mutations.

\begin{tabular}{|c|c|c|c|c|c|c|c|c|}
\hline \multirow[b]{2}{*}{ transcript } & sition & \multirow{2}{*}{$\begin{array}{l}\text { Present } \\
\text { in } \\
\text { patient }\end{array}$} & \multirow{2}{*}{ Exon } & \multirow{2}{*}{ Impact } & \multicolumn{2}{|c|}{ Result on } & \multirow{2}{*}{ Validation } & \multirow{2}{*}{ Reference } \\
\hline & protein & & & & transcript & protein & & \\
\hline c.312_321delinsAT & p. $\left(\right.$ Pro104Profs $\left.{ }^{\star} 1\right)$ & 3 & $4 / 9$ & $\begin{array}{l}\text { frameshift \& } \\
\text { PTC }\end{array}$ & NMD & Absent & NA & $\begin{array}{c}\text { Tiranti et al. } \\
1998\end{array}$ \\
\hline c. $588+1 \mathrm{G}>\mathrm{A}$ & p.(?) & 2 & $6 / 9$ & $\begin{array}{l}\text { exon } 6 \text { skipping } \\
\text { \& PTC }\end{array}$ & NMD & Absent & $\begin{array}{l}\text { RT-PCR } \\
\text { (cDNA), } \\
\text { AGE }\end{array}$ & $\begin{array}{l}\text { Pequignot et al. } \\
2001\end{array}$ \\
\hline c. $823 \_833+7 \mathrm{del}$ & p.(?) & 1,2 & $8 / 9$ & $\begin{array}{l}\text { exon } 8 \text { skipping } \\
\text { \& frameshift }\end{array}$ & $\begin{array}{l}\text { Reading frame } \\
\text { lacking the } \\
\text { termination } \\
\text { codon }\end{array}$ & $\begin{array}{l}\text { Aberrant } \\
\text { C-terminal } \\
\text { part of the } \\
\text { protein }\end{array}$ & $\begin{array}{l}\text { RT-PCR } \\
\text { (cDNA), } \\
\text { AGE }\end{array}$ & $\begin{array}{c}\text { Williams et al. } \\
2001\end{array}$ \\
\hline c.845_846del & p. $\left(\right.$ Ser282Cysfs $\left.{ }^{\star} 9\right)$ & 1,3 & $9 / 9$ & $\begin{array}{c}\text { frameshift \& } \\
\text { PTC }\end{array}$ & NMD & Absent & NA & $\begin{array}{c}\text { Tiranti et al. } \\
1998\end{array}$ \\
\hline
\end{tabular}

All transcript positions are indicated with respect to NM_003172.3. Abbreviations: AGE - agarose gel electrophoresis; NA - not available; NMD - nonsense-mediated decay; PTC - premature termination codon; RT-PCR - real-time PCR. 
Table 2

Phenotypic features of the reported patients.

\begin{tabular}{|c|c|c|c|c|c|c|c|}
\hline Case & $\begin{array}{c}\text { Age of } \\
\text { onset } \\
(\text { sex })\end{array}$ & Outcome & Neuromuscular & Growth & Metabolic & Brain MRI lesions & Others \\
\hline patient 1 & $\begin{array}{l}6 \\
\text { months } \\
(\mathrm{M})\end{array}$ & $\begin{array}{l}\text { died } \\
\text { at } 1 \text { year }\end{array}$ & hypotonia & $\begin{array}{c}\text { FTT, } \\
\text { hypotrophy }\end{array}$ & $\begin{array}{c}\uparrow \text { serum and CSF } \\
\text { lactate; } \\
\uparrow \text { excretion of } \\
\text { metabolites of the } \\
\text { Krebs cycle and } \\
\text { respiratory chain; } \\
\downarrow \text { activities of } \\
\text { complexes II and IV }\end{array}$ & $\begin{array}{l}6 \text { months - T2W areas of bilateral } \\
\text { high signal predominantly in the } \\
\text { WM supra and infratentorially, with } \\
\text { acute manifestations, no changes in } \\
\text { basal ganglia } \\
11 \text { months - T2W progression of } \\
\text { changes, acute large areas of the } \\
\text { pathologic bilateral high signal of } \\
\text { periventricular to central WM supra } \\
\text { and infratentorially, demyelination } \\
\text { of brainsterm, midbrain and basal } \\
\text { ganglia. }\end{array}$ & hypertrichosis \\
\hline patient 2 & $\begin{array}{l}4 \text { years } \\
(\mathrm{M})\end{array}$ & $\begin{array}{l}\text { alive, } \\
16 \text { years }\end{array}$ & $\begin{array}{l}\text { hypotonia, } \\
\text { ataxia, ptosis, } \\
\text { epilepsy }\end{array}$ & hypotrophy & $\begin{array}{l}\uparrow \text { serum and CSF } \\
\text { lactate; } \\
\downarrow \text { activities of } \\
\text { complexes I, I-III } \\
\text { and IV }\end{array}$ & $\begin{array}{l}\text { T2W hyperintensive signal of WM, } \\
\text { cerebellar hemisphere, brainstem, } \\
\text { periaqueductal grey mater }\end{array}$ & hypertrichosis \\
\hline patient 3 & $\begin{array}{c}18 \\
\text { months } \\
\text { (F) }\end{array}$ & $\begin{array}{c}\text { alive, } \\
2.5 \text { years }\end{array}$ & $\begin{array}{l}\text { hypotonia, } \\
\text { breathing and } \\
\text { swallowing } \\
\text { difficulties }\end{array}$ & $\begin{array}{c}\text { FTT, } \\
\text { hypotrophy }\end{array}$ & $\begin{array}{l}\uparrow \text { serum and CSF } \\
\text { lactate; } \\
\uparrow \underline{\text { CSF 3-OH }} \\
\text { butyrate }\end{array}$ & $\begin{array}{l}\text { T2W symmetric hyperintesive signal } \\
\text { changes of basal ganglia, midbrain, } \\
\text { brainstem, periaqueductal region }\end{array}$ & $\begin{array}{l}\frac{\text { facial }}{\text { dysmorphism, }} \\
\text { hypertrichosis, } \\
\text { macrocephaly }\end{array}$ \\
\hline
\end{tabular}

Distinct/atypical features of the patient are underlined. Abbreviations: CSF - cerebrospinal fluid, FTT - failure to thrive, WM - white matter

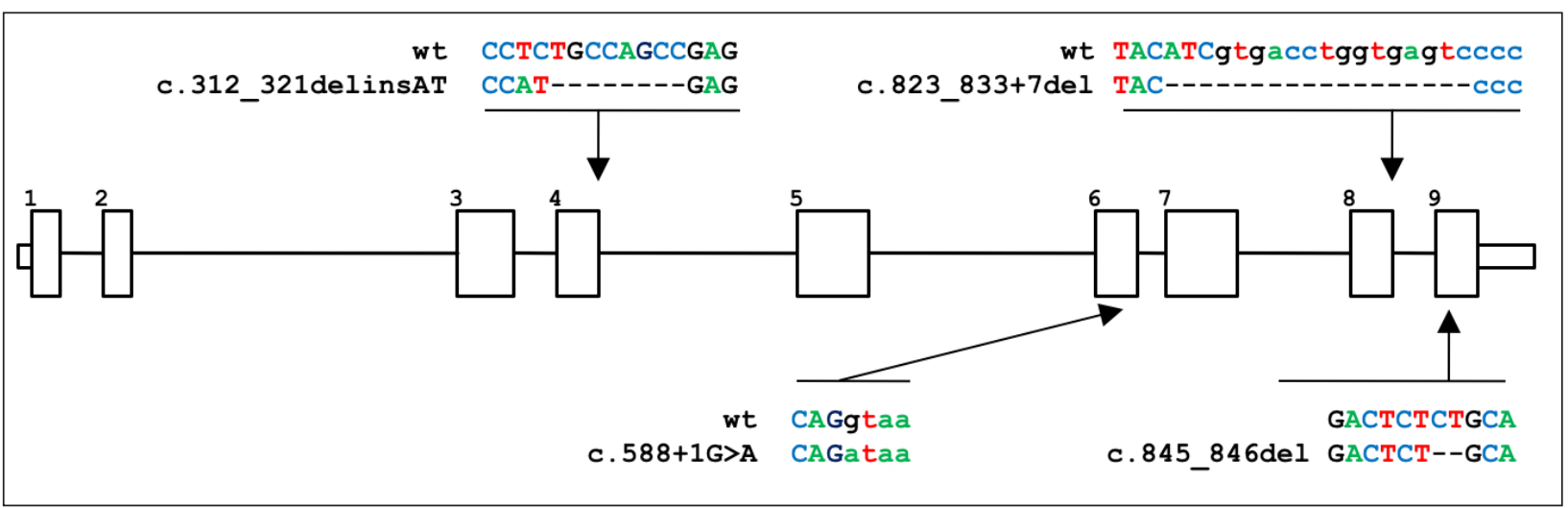

Figure 3. Schematic representation of positions of the mutations in the SURF1 gene. Thick boxes represent exons, thin boxes represent untranslated regions and lines represent introns. The upper-case characters denote exonic nucleotides, the lower-case characters represent intronic nucleotides and dashes (-) act as placeholders for deleted nucleotides.

component of the mitochondrial respiratory chain that mediates transfer of electrons to oxygen. The COX deficiency is one of the major causes of the LS, where up to $75 \%$ of patients harbor mutations in the SURF1 gene (Gerards et al. 2016). Moreover, SURF1 gene mutations have been identified panethnically (Caucasian, Asian, Hispanic, Arabic) (Lee et al. 2012; Maalej et al. 2018).

Activities of respiratory chain components were measured in samples of muscle tissue obtained from patient 1 and patient 2 . We observed $\sim 50 \%$ decrease in activities of the COX and complex II of the patient 1 in comparison with the measurements in healthy controls. In patient 2, decreased activities of COX and complexes I, I-III were discovered (Mitolab, Prague). These measurements are in agreement with other findings, where impaired activity of other components of respiratory chain has been reported along with COX (Pecina et al. 2003; Tay et al. 2005). Further studies are required to fully elucidate this phenomenon. 
Patient 1 harbored the mutations c.[845_846del]; $\left[823 \_833+7 \mathrm{del}\right]$. The first mutation c.845_846del, inherited on paternal allele, is a deletion of two nucleotides localized in the last exon of SURF1. The mutation leads to frameshift that results in introduction of 8 novel amino acid residues followed by premature termination codon (PTC) at position 867 and it is predicted to produce protein truncated at position 291. This deletion belongs among the most common mutations found in previously reported cases (Tiranti et al. 1998; Pequignot et al. 2001; Lee et al. 2012).

The second mutation c.823_833+7del, originating in maternal allele, has been reported for the first time by Williams et al. (2001). The deletion of 18 nucleotides results in removal of the whole splice donor site of SURF1 exon 8. The effect on mRNA processing has been studied using 3'RACE to amplify exons 7-9 from patient's cDNA followed by agarose gel electrophoresis and sequencing of the products, showing that the deletion results in a mRNA lacking exon 8 (Williams et al. 2001). Skipping of the exon 8 is predicted to lead to frameshift and production of mRNA molecules, which do not contain any termination codon in the reading frame. The mutation has been found in a patient presenting with typical features of LS, such as symmetrical lesions of the basal ganglia, failure to thrive, elevated CSF and serum lactate, growth retardation, strabismus, progressive hypotonia and hypertrichosis.

It has been suggested, that having truncating mutations, such as c.845_846del and c.823_833+7del, close to the C-terminus may support some residual function, resulting in a milder phenotype (Lee et al. 2012). This was not the case for patient 1 in this report, who presented with an early onset of symptoms in 6 months followed by a severe clinical course. Moreover, the MRI findings at the age of 7 months lacked the typical signs of Leigh syndrome, such as pathologic hyperintense signal in the basal ganglia.

Patient 2 carried mutations c.[312_321delinsAT]; [823_833+7del]. The mutation c.312_321delinsAT is a complex rearrangement localized at the end of exon 4 which removes 10 nucleotides and inserts two novels. In result, premature termination codon is introduced into position 105 of the reading frame and mRNA is expected to be degraded by nonsense-mediated decay (NMD) machinery. Presence of the mutation has been first reported in two unrelated patients presenting with typical LS (Tiranti et al. 1998) and the mutation is a frequent cause of LS in Caucasian ethnicity (Lee et al. 2012). The second mutation was described above. The clinical phenotype of the patient is typical for Leigh syndrome. Interestingly, the same geno- type has been reported in a patient by Williams et al. (2001), but with earlier onset. The proband is currently 16 years old, having one of the longest life-spans of LS patients with defective SURF1 reported until now (Lake et al. 2016).

Patient 3 was found to carry mutations c. [588+1G]; [845_846del]. The first mutation $c .588+1 G>A$ is a substitution of the first nucleotide of intron 6 and leads to abolition of the a highly conserved GT dinucleotide of the splice donor site. To discover the impact of the mutation on mRNA splicing, RNA from patient's blood has been evaluated by RT-PCR and sequencing, where presence of exon 6 skipping has been discovered (Pequignot et al. 2001). Messenger RNA lacking exon 6 contains premature termination codon at position 183 which is expected to trigger NMD and cause degradation of the faulty mRNA molecule. The second c.845_846del mutation was described above. Until the 2.5 years of age, the proband has been presenting a typical LS phenotype.

Leigh syndrome is a genetically heterogeneous disorder presenting broad spectrum of symptoms. A lot of efforts have been done to establish the genotypephenotype correlation for majority of $>75$ genes involved in LS, but no definite associations between disease course and affected gene have been defined yet (Sofou et al. 2018). Most of the patients harboring mutations in SURF1 present the typical LS with early-onset disease, lactic acidosis, and classical brain lesions. However, patients with SURF1 mutations presenting with delayed onset, milder disease course and longer life-span have been reported, as well (Lee et al. 2012). The phenotypes of our patients were in agreement with the above mentioned observations. Absence of the lesions in the basal ganglia in the patient 1 , despite early-onset of his disease, was the only observed exception.

Currently, no standard therapy is available for LS, making LS an incurable condition with poor prognosis in most cases. Usually, patients might benefit from supplementation of vitamins (e.g. thiamine, riboflavin, folinic acid), coenzyme Q10 and its derivates, pyruvate, dichloroacetate and ketogenic diet. However, many efforts and resources are being allocated for a search for the cure and a new treatment strategies are emerging (Chen et al. 2017). In some individual cases including patients with SURF1 mutations, drugs targeting parts of the mitochondrial respiratory chain, such as EPI-743 (derivative of coenzyme Q10), have been able to stop the progression of the disease or even temporarily improve the patient's condition (Martinelli et al. 2012). However, the therapy with EPI 743 is not available in Slovakia at the moment. 
In conclusion, we identified genetic etiology of three studied patients with LS from Slovakia, where four different mutations in the SURF1 gene were identified in three families. It seems that SURF1 mutations play an important role in the etiology of LS in Slovakia. Our data showed that patients with unclear LS phenotype (patient 1) can benefit from testing by whole exome sequencing method. In the case of the other probands, who had the typical phenotype with progressive hypotonia, increased lactate levels and characteristic MRI features, Sanger sequencing of SURF1 gene was the preferred method of DNA analysis.

\section{Acknowledgement}

This work was supported by Slovak Research and Development Agency (APVV0187-12), by the Research \& Development Operational Program funded by the ERDF (BIOMED, ITMS: 26240220087), and VEGA (2/0083/17). Web resources: dbSNP150: http://www. ncbi.nlm.nih.gov/SNP; 1000 Genomes: https://www. ncbi.nlm.nih.gov/variation/tools/1000genomes; ESP: http://evs.gs.washington.edu/EVS; ExAC: http://exac. broadinstitute.org; CADD: http://cadd.gs.washington. edu; PolyPhen2: http://genetics.bwh.harvard.edu/ pph2; SIFT: http://sift.jcvi.org.

\section{References}

Chen L, Cui Y, Jiang D, Ma CY, Tse HF, Hwu WL, Lian Q. Management of Leigh syndrome: Current status and new insights. Clin Gen, Epub ahead of print, 2017.

Gerards M, Sallevelt SC, Smeets HJ. Leigh syndrome: Resolving the clinical and genetic heterogeneity paves the way for treatment options. Mol Genet Metab 117, 300-312, 2016.

Guo Y, Ye F, Sheng Q, Clark T, Samuels DC. Three-stage quality control strategies for DNA re-sequencing data. Brief Bioinform 15, 879-889, 2013.

Lake NJ, Compton AG, Rahman S, Thorburn DR. Leigh syndrome: One disorder, more than 75 monogenic causes. Ann Neurol 79, 190-203, 2016.

Lee IC, El-Hattab AW, Wang J, Li FY, Weng SW, Craigen WJ, Wong LJ. SURF1-associated Leigh syndrome: a case series and novel mutations. Hum Mutat 33, 1192-1200, 2012.

Leigh D. Subacute necrotizing encephalomyelopathy in an infant. J Neurol Neurosurg Psychiatry 14, 216-221, 1951.

Maalej M, Kammoun T, Alila-Fersi O, Kharrat M, Ammar M, Felhi R, Mkaouar-Rebai E, Keskes L, Hachicha M, Fakhfakh F. Cytochrome C oxydase deficiency: SURF1 gene investigation in patients with Leigh syndrome. Biochem Biophys Res Commun 497, 1043-1048, 2018.

Martinelli D, Catteruccia M, Piemonte F, Pastore A, Tozzi G, Dionisi-Vici C, Pontrelli G, Corsetti T, Livadiotti S, Kheifets V, Hinman A, Shrader WD, Thoolen M, Klein MB, Bertini E, Miller G. EPI-743 reverses the progression of the pediatric mitochondrial disease-genetically defined Leigh Syndrome. Mol Genet Metab 107, 383-388, 2012.

McLaren W, Gil L, Hunt SE, Riat HS, Ritchie GR, Thormann A, Flicek P, Cunningham F. The Ensembl Variant Effect Predictor. Genome Biol 17, 122, 2016.

Paila U, Chapman BA, Kirchner R, Quinlan AR. GEMINI: integrative exploration of genetic variation and genome annotations. PLoS Comput Biol 9, e1003153, 2013.

Pecina P, Capkova M, Chowdhury SK, Drahota Z, Dubot A, Vojtiskova A, Hansikova H, Houstkova H, Zeman J, Godinot C, Houstek J. Functional alteration of cytochrome c oxidase by SURF1 mutations in Leigh syndrome. Biochim Biophys Acta 1639, 53-63, 2003.

Pequignot MO, Desguerre I, Dey R, Tartari M, Zeviani M, Agostino A, Benelli C, Fouque F, Prip-Buus C, Marchant D, Abitbol M, Marsac C. New splicing-site mutations in the SURF1 gene in Leigh syndrome patients. J Biol Chem 276, 15326-15329, 2001.

Rahman S, Blok RB, Dahl HH, Danks DM, Kirby DM, Chow CW, Christodoulou J, Thorburn DR. Leigh syndrome: clinical features and biochemical and DNA abnormalities. Ann Neurol 39, 343-351, 1996.

Skopkova M, Hennig F, Shin BS, Turner CE, Stanikova D, Brennerova K, Stanik J, Fischer U, Henden L, Muller U, Steinberger D, Leshinsky-Silver E, Bottani A, Kurdiova T, Ukropec J, Nyitrayova O, Kolnikova M, Klimes I, Borck G, Bahlo M, Haas SA, Kim JR, Lotspeich-Cole LE, Gasperikova D, Dever TE, Kalscheuer VM. EIF2S3 Mutations Associated with Severe X-Linked Intellectual Disability Syndrome MEHMO. Hum Mutat 38, 409-425, 2017. 
Sofou K, de Coo IFM, Ostergaard E, Isohanni P, Naess K, De Meirleir L, Tzoulis C, Uusimaa J, Lonnqvist T, Bindoff LA, Tulinius M, Darin N. Phenotype-genotype correlations in Leigh syndrome: new insights from a multicentre study of 96 patients. J Med Genet 55, 21-27, 2018.

Tan A, Abecasis GR, Kang HM. Unified representation of genetic variants. Bioinformatics 31, 2202-2204, 2015.

Tay SK, Sacconi S, Akman HO, Morales JF, Morales A, De Vivo DC, Shanske S, Bonilla E, DiMauro S. Unusual clinical presentations in four cases of Leigh disease, cytochrome C oxidase deficiency, and SURF1 gene mutations. J Child Neurol 20, 670-674, 2005.

Tiranti V, Hoertnagel K, Carrozzo R, Galimberti C, Munaro M, Granatiero M, Zelante L, Gasparini P, Marzella R, Rocchi M, Bayona-Bafaluy MP, Enriquez JA, Uziel G, Bertini E, Dionisi-Vici C,Franco B, Meitinger T, Zeviani M. Mutations of SURF-1 in Leigh disease associated with cytochrome c oxidase deficiency. Am J Hum Genet 63, 1609-1621, 1998.

Wang J, Raskin L, Samuels DC, Shyr Y, Guo Y. Genome measures used for quality control are dependent on gene function and ancestry. Bioinformatics 31, 318-323, 2015.

Williams SL, Taanman JW, Hansikova H, Houstkova H, Chowdhury S, Zeman J, Houstek J. A novel mutation in SURF1 causes skipping of exon 8 in a patient with cytochrome c oxidase-deficient Leigh syndrome and hypertrichosis. Mol Genet Metab 73, 340-343, 2001. 